\title{
Influence of soil reducing capacity on the mechanisms driving mercury behaviour
}

\author{
MATHIEU DEBURE ${ }^{1}$ AND SYLVAIN GRANGEON ${ }^{2}$ \\ ${ }^{1}$ BRGM - THE FRENCH GEOLOGICAL SURVEY \\ ${ }^{2}$ BRGM (French Geological Survey) \\ Presenting Author: m.debure@brgm.fr
}

Due to climate change, the frequency of intense droughts and flooding events will certainly increase significantly. Such events will influence soil properties, including soil humidity level. Therefore, soil water saturation/desaturation cycles and hence soil reducing/oxidising cycles will be modified. This will in turn modify the speciation and geochemical cycle of chemical elements present in soil. Such modifications will especially affect elements that are redox-sensitive, for example mercury $(\mathrm{Hg})$, either directly (by direct change in speciation) or indirectly (through the modification of its carrier phases - e.g. organic matter, clays, $\mathrm{Mn}$ and $\mathrm{Fe}$ oxy(hydr)oxides or of bacterial communities).

We investigated the mechanisms of interactions between divalent aqueous $\mathrm{Hg}$ and two rock samples from the Albian Tégulines Clay (France) experiencing contrasting in situ redox conditions, with the aim of quantifying the potential changes in $\mathrm{Hg}$ speciation and sorbed/dissolved distribution upon interaction with the solid. The sample closer to the surface $(7.7 \mathrm{~m}$ depth) was under oxidizing conditions and contained goethite and siderite, while the deeper one (21.2 $\mathrm{m}$ depth) was under reducing conditions and contained siderite, together with pyrite and magnetite. The redox state of the samples was preserved throughout the study by working under $\mathrm{O}_{2}$-free conditions.

The two samples had similar $\mathrm{Hg}$ retention capacity. However, the mechanisms of interaction differed. In the oxidized sample, the retention was due to reversible adsorption on the mineral phases and no change in $\mathrm{Hg}$ redox state occurred. In contrast, upon interaction with the deeper and reduced sample, part of $\mathrm{Hg}$ was reduced to dissolved elemental $\mathrm{Hg}$. This reduction was attributed to redox interactions with $\mathrm{Fe}(\mathrm{II})$ contained in magnetite and siderite and highlights the influence of mineralogy on the geochemical cycle of $\mathrm{Hg}^{[1]}$.

This study quantify the impact of the mineralogy on the mobilization of $\mathrm{Hg}$. However, the soil is a complex environment both because of the diversity of the mineral phases that compose it, and because of the exacerbated redox fluctuations at the interface between unsaturated and saturated zones promoting (a)biotic reduction. Understanding these processes is imperative to assess the $\mathrm{Hg}$ cycling in environment.

${ }^{[1]}$ Debure et al. (2020), Sci. Total Environ. (707), 136069 